\title{
J
}

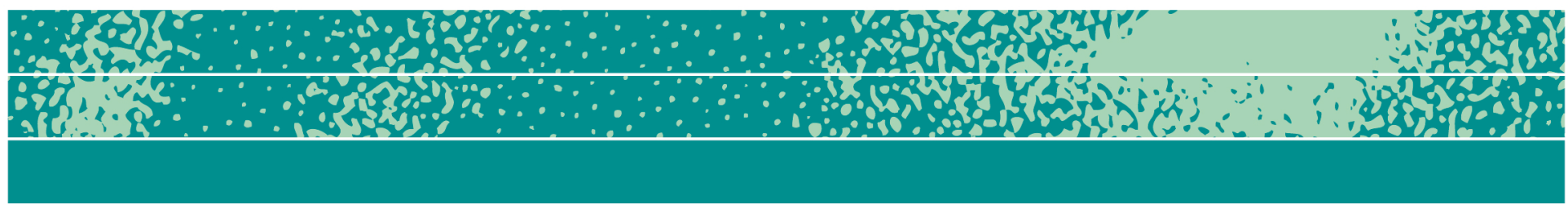

\section{Field Report: Implementing a Social Science Capability in a Marine Corps Organization}

\author{
Kerry B. Fosher
}

\begin{abstract}
In 2010 the Marine Corps started a small, experimental capability, the Translational Research Group (TRG), to help the organization more effectively integrate social science and scientists into decision-making. In contrast to other recent military social science programs, TRG focuses inward, on Marines and Marine Corps organizations. The group houses fieldwork-focused social scientists within a military organization so they can understand the problem-framing context and implementation processes, but provides significantly greater academic freedom and protection from over-tasking than is the norm in military research settings. Researchers conduct independently designed projects, support curriculum development, and provide social science advice to a broad scope of military organizations. Although leadership support for the group has been strong, there have been significant impediments to fully institutionalizing the capability. This field report provides an outline of the background and design of the group and examines some of the key challenges encountered during implementation.
\end{abstract}

\section{Keywords}

military, implementation, action anthropology, translational research, practicing anthropology

Page 1 of 20

JBA 7(1): 133-152

Spring 2018

(C) The Author(s) 2018 ISSN 2245-4217

www.cbs.dk/jba 


\section{Overview}

This field report describes the ongoing process of trying to implement a research and scientific advisory capability within a large organization. In 2010 the Marine Corps launched a small experiment in integrating social science and social scientists into organizational decision-making. ${ }^{1}$ The experiment was a response to concerns raised by senior leaders and researchers about existing patterns of how research was conducted and how results and expertise were leveraged (see Fosher 2015 for a more complete overview of these issues).

Our first set of concerns, those about the conduct of research, centered on the ability of researchers to balance practical understanding of military organizations with scientific rigor and autonomy. Developing an understanding of any one military organization is daunting. Understanding them within the context of the Department of Defense (DoD), let alone the full scope of relationships with other government, industrial, and academic organizations, is an overwhelming task that warrants some illustration. By its own estimates, the number of active and reserve military personnel and civilian personnel in DoD is roughly 2.8 million (United States Department of Defense 2017). The number of contractors supporting DoD is difficult to calculate (Elmendorf 2015). However, the 700,000 is a common estimate (Dilulio 2014). ${ }^{2}$ The end result is about 3.5 million people spread out across the globe in disaggregated organizational structures. So, expecting a new researcher to understand even the DoD level of context is equivalent to expecting them to quickly comprehend the entire population and cultural patterns of a large urban area or small country. The scale of the organization also makes it difficult to make definitive statements about how "the military" does things, which creates challenges in bringing external researchers up to speed on the research and implementation contexts.

Social science research conducted by researchers who did not work within military organizations sometimes suffered from lack of understanding of the military context with its complex array of confounding factors. External researchers' limited understanding of the

\footnotetext{
${ }^{1}$ The views presented in this report are the author's alone and do not represent the position of the United States Marine Corps.

${ }^{2}$ This number appears frequently in news articles and websites. All seems to trace back to John Dilulio's analysis of two reports by the Government Accountability Office in which he attempts to estimate full time equivalent personnel. His estimate is the most reasonable available, but he is clear that it is an estimate. Who counts as a defense contractor and for what percentage of their time is complicated by factors such as subcontracting, individuals working on many different projects, only some of which are related to DoD, and different funding categories. An accurate head count is not only impractical, but also not particularly useful in understanding the presence and influence of contractors in the sector.
} 
supporting establishment ${ }^{3}$ bureaucracy also meant that they often communicated results and recommendations that were not viable within existing implementation processes. ${ }^{4}$ Yet, projects conducted by personnel within military organizations sometimes suffered from other kinds of problems - weak problem framing, mismatched subject matter expertise, and constraints on questions, methods, and results. Both internal and external approaches to conducting research tended to be influenced by institutional bias toward experimental design, quantitative results, and highly structured contact between researchers and military personnel. Both approaches made it difficult to challenge the assumptions and biases inherent in government calls for research. Both approaches also tended to frustrate researchers and practitioners ${ }^{5}$ and too often yielded results that were difficult to implement.

Our second set of concerns, those about leveraging expertise, were similarly focused on existing expertise-related practices in military organizations. A full examination of the discourses and practices related to expertise in military organizations is beyond the scope of this report, but a few comments are necessary. By the time we were setting up the research group, I was coming to understand some aspects of how topical and scientific expertise are viewed. Decision-making in military organizations is usually rushed. When scientific or "subject matter expert" (SME) advice is sought, leaders have little or no time to find appropriate expertise, let alone assess the credentials of the person(s) who ends up giving the advice. The default orientation to expertise is to view it as topical, as subject matter expertise. Civilian SMEs generally are hired for knowledge that is (or at least is presumed to be) already in their heads.

While I question whether or not it is intentional, SMEs are effectively treated as a consumable commodity. Few military organizations have the necessary personnel policies in place that would allow a topical expert to actively maintain or further develop their

\footnotetext{
${ }^{3}$ In this report, the term "supporting establishment" is used as a convenience in contrasting "operating forces" with organizations whose primary role is to support the development and maintenance of the operating forces or those that are primarily involved with policy and management at higher levels within the service. Marine Corps personnel use a finer-grained set of distinctions with more than two categories.

${ }^{4}$ While it is usually not intentional, military organizations often adopt research results "cafeteria style," taking on only those findings and recommendations that are in alignment with existing institutional orientations. They also tend to alter recommended courses of action to suit existing processes, policies, and venues. These adoption patterns mean that critical aspects of recommendations may be stripped off before or during implementation, leading to unexpected outcomes. However, it is possible to learn about these patterns and design recommendations that are more likely to withstand pressures during implementation.

${ }^{5}$ For the purposes of this report, the term "practitioner" is used to refer to military and civilian personnel in military organizations.
} 
expertise and professional networks. There also is a fairly common practice of assigning responsibility for topical expertise based on position rather than credentials. This practice is applied to both military and civilian personnel. In this approach to expertise, if you hold a particular position or are assigned to a particular set of tasks, part of your job is to become the organization's expert in one or more topics. It is surprisingly common for people with little or no relevant background and no access to scientific literature to be assigned to become the expert on something. The individual thus assigned may have some background in research or s/he may simply be the only person who has the spare time to look into an issue. Most importantly, individuals assigned to become experts on a topic often do not have the authority to say no or to redirect the organization to a more appropriate source (Fosher 2015). It is important to recognize that this approach is understood to be problematic. I have heard leaders of military organizations express concern about their organizations being only "Wikipedia deep" or "Google deep" on issues. However, military leaders are trained to understand that no activity will ever be perfectly run and no knowledge-base will ever be complete. They learn to make judgments about where to assume risk. Given the pace of decision-making and the difficulty of hiring and contract processes used to bring in additional voices, this approach to expertise is often a risk they judge to be necessary.

The idea of scientific expertise does not have the well-worn channels of discourse and practice seen with topical expertise. In my experience, with a few exceptions, ${ }^{6}$ scientists and researchers were thought of as mostly being outside government, in universities, think tanks, or industry. There might be people with scientific backgrounds working in other roles - analyst, program manager, etc. - within an organization, but the idea of them actually doing science always seemed to bring people up short. The idea of internal personnel doing science wasn't necessarily seen in a negative light, it was just outside the normal frame of thinking. There also was a strong tendency to conflate topical expertise and technology development with scientific expertise. We have been very deliberate in our efforts to shift this discourse. We emphasized the importance of theory and method and the value of different disciplines. We made distinctions, such as the idea that subject matter experts are brought in because of what they already know, but scientists are brought in because of what they can find out, because of their ability to solve novel problems and produce new knowledge. We had some

\footnotetext{
${ }^{6}$ Personnel in military organizations usually are aware that there are operations researchers, data analysts, and psychologists working somewhere in the organization. They also are usually aware that there are faculty in professional military education organizations. Many are less aware of finer grained distinctions such as whether an activity is analysis or research and whether an individual is working as an analyst, scientist, or clinician.
} 
successes with these discursive shifts, although there is a long way yet to go. Making necessary changes in associated personnel practices and policies is an even more complex task. While we have had some successes in creating scientifically oriented position descriptions for social and behavioral scientists in Marine Corps organizations, there are still significant challenges. Some of these are described in the section on implementation challenges below.

In addition to addressing the discursive concerns above, we made the decision to frame the group's capability on field social science in an effort to break the cycle of the historical relationship between anthropology and the U.S. Department of Defense (DoD). While a full examination of that relationship is beyond the scope of this report, it is reasonable to say that it was fraught with legitimate concerns about the ethical and political implications of social scientists working with or for military and intelligence organizations (Albro, et al. 2012; Deitchman 2014 [1976]; Peacock, et al. 2007; Price 2011; Rubinstein, et al. 2012; Rubinstein 2012). We wanted to see if it was possible to create a space where researchers from fieldwork-focused social science disciplines could work within their respective codes of ethics and have the autonomy necessary to ensure professional integrity. We also were aware that the military's increased interest in what was referred to as "cultural training and education" was, in fact, a symptom of a broader problem. If a broader range of social scientists, holding appropriate roles, ${ }^{7}$ had been present within the institution we felt that the direction of culture-related programs, as well as many other programs and decisions, might have been different. So, while we wanted to build a capability for research and science advising, the broader purpose of the setting up the group was to create the kind of environment where anthropologists, geographers, sociologists, and other researchers from scarce disciplines would feel comfortable making a career and where they could influence thinking and action over the coming decades. ${ }^{8}$

\footnotetext{
${ }^{7}$ DoD and the intelligence community employed many cultural anthropologists, archaeologists, geographers, sociologists, etc. in the time between the last phase of intense institutional interest in culture (the 1960s) and the present. It is not possible to track all the different positions they held. However, in most cases their roles do not seem to have provided them sufficient opportunity to shape programs and leadership thought in ways that more fully integrated contemporary perspectives from their disciplines into their organization's decision-making processes. With regard to anthropology, the discipline's reluctance to engage at the institutional level, while understandable, has exacerbated the situation in some ways that are not always visible outside military organizations. It has led to a situation where what constitutes anthropology and appropriate roles for anthropologists, or even what credentials make one an anthropologist, are defined by people who may not have the longterm interests of the discipline as a primary concern.

${ }^{8}$ Although this was not a key element in discussions about setting up the group, I also wanted to demonstrate the value of fieldwork-focused social science for the
} 
The result of our deliberations about the issues above was the formation of the Translational Research Group (TRG). The group was designed to house social scientists within a military organization so they would understand the context and implementation processes, but have significantly greater academic freedom and protection from other demands on their time than the norm. We wanted them close enough to the tyranny of the urgent to understand how it affected the ways their results might be understood and implemented. Yet, we also needed to protect them from the urgency and the organization's tendency to indulge in crisis mode.

We drew on the concept of action anthropology and the model of translational research from medicine, which focuses on moving basic research into use as quickly as possible (Rubinstein 1986; Woolf 2008). The group's approach emphasizes close collaboration between researchers and practitioners. While researchers retain control of the research design, collaboration with practitioners can help them develop research questions and, later, recommendations that more closely track with practitioner needs and implementation context. They also learn how to communicate research results in forms accessible and usable by practitioners. In turn, the practitioners become more aware of the constraints and processes of research, making them more adept at asking viable research questions and taking advantage of results.

The translational research model in medicine has been critiqued for masking a dangerous slide away from basic research and toward a purely applied research agenda (Jogalekar 2012). Despite these critiques, we felt that we could draw on the best aspects of the action anthropology/translational model, creating a middle space between basic and applied research. In this space, we hoped to conduct field social science research that was characterized by:

- theoretically and methodologically rigorous design

- critical analysis of problem framing and existing assumptions

- close consultation with practitioners familiar with the problems, contextual factors, and implementation processes associated with the research

- long term, multi-context contact with research participants

military to study itself. In particular, I wanted to contrast our use of social science with more problematic programs, such as the operational support function of the Army's Human Terrain System (HTS). For an overview of some of the concerns about HTS see Albro, Robert, et al. 2009 AAA Commission on the Engagement of Anthropology with the US Security and Intelligence Communities (CEAUSSIC) Final Report on The Army's Human Terrain System Proof of Concept Program. American Anthropological Association. 
- research designs and reporting that were attentive to the institutional context and discourses in which results might be assessed and implemented.

One particularly important aspect of designing the capability was that we retained the autonomy to choose our own projects rather than simply respond to tasking. This was established by decoupling funding for salaries, travel, and other operating costs from specific projects and by the director requiring autonomy as a condition of setting up the group. As within any government organization, there are limits to how much autonomy can be promised. (We do operate within certain parameters in that we have to focus on issues that are relevant to the organization and within our available funds.) This freedom has meant that we do not have to conduct research on poorly conceptualized buzzwords or design research in ways that suit institutional comfort zones. We also ensured that, because researchers would remain in the institutional context, it would be more possible for them to provide long-term support for implementation, something that was hard for external researchers to do once funding for their specific project had ended. This long-term presence also could facilitate developing the relationships necessary for researchers to be involved in advising leaders and participating in problem framing. The weakness in this aspect of the group's design is that it is heavily dependent on senior leader buy-in and trust. A change in the group's leadership or in the composition of the organizational leadership above the group could make it very difficult to maintain the autonomy.

The group was established within the Marine Corps center that handles culture and language training and education. The decision to host TRG within the culture center made sense in terms of available personnel billets, contracts, space, and, most importantly, the leadership. Both the culture center's leadership and the next level of leadership were involved in thinking through the challenges in the Marine Corps' research capability. While being in the culture center made sense from the standpoint of launching the capability in a context where leadership understood the complexity of the experiment, this choice of location did create challenges, some of which are described below.

During the first seven years of the group's existence, we have conducted qualitative research on a broad range of topics including Marine concepts of stress and resilience, the value of advanced degrees for enlisted personnel, how Marine understanding and use of culturerelated training changes over the course of the deployment cycle, critical analysis of DoD narratives about the future, and problems with DoD's ability to effectively leverage scientific expertise. We also have supported the culture center's curriculum development and assessment efforts. Although these efforts have been productive, the most important and effective work of the group has been in scientific advising. By being 
present in meetings, available to answer calls and emails or have a quick chat over coffee, and through various other interactions, we have been able to provide perspectives from our various disciplines as different elements of the Marine Corps make decisions.

Science advising gives us the opportunity to have a voice in discussions and decisions about the development of research agendas (not only for our own group), the way programs are shaped, how research claims are vetted, and what recommendations are implemented. Sometimes we are advising from our own disciplinary perspectives, but sometimes we make recommendations for the organization to reach out to experts in other fields so that they get the best possible advice. Our advisory work makes it possible for us to support implementation of research results, a process that sometimes takes episodic attention over a period of several years. It also makes it possible for us to help Marine Corps leaders shape which questions get asked at the beginning of initiatives or programs, something which can fundamentally alter the approach of the organization.

A full description of the topics and modes of our science advising efforts would be beyond the limitations of a field report. However, we have advised on topics aligned with our research, as well as other matters, such as the weakness of generational cohort research as a basis for military decision-making, limitations of functional magnetic resonance imaging (a type of "brain scan") technology for understanding the effect of training and education, how to incorporate disease and public health issues into concepts of the future operating environment, value conflicts, approaches to ethics in military education, and many other issues. Throughout all our efforts on research, curriculum, and science advising, we have focused not only on giving sound advice, but also on integrating sound, contemporary social science theory into decision-making. I don't want to give the impression that we are always successful in our efforts. We are not. No group ever is. In fact, we fail or have only partial success more often than we fully succeed. However, persisting in the effort is part of the longer-term goal of integrating social science and social scientists more fully in how the organization does business.

\section{Implementation challenges}

Initial support for the group was strong among civilian and military leaders within the Marine Corps. Many shared scientists' concerns about existing models of research. Publications and advising by the group's researchers were reasonably well received and used, if not always perfectly. However, we encountered obstacles that prevented full development of the group and execution of the intended research agenda. From the standpoint of creating a sustainable organization, we had 
funding, positioning, and personnel structure challenges, all of which were heavily influenced by existing patterns of operation within DoD. Of these issues, positioning and personnel structure, rather than funding, were the most significant.

\section{Funding:}

While the group has not experienced the major cuts of some organizations, federal budget sequestration and other factors have taken their toll. The group voluntarily cut two positions to support overall cuts in the larger organization. While difficult, these cuts had the benefit of reducing my administrative burden as the group's director and we adapted well. More significantly, it has become very hard to predict the availability of travel funds for both government and contract personnel, making it difficult to plan large-scale research projects. Likewise, federal contracting regulations are opaque and we are vulnerable to the changing interpretations of the rules by the government personnel who manage the contracts. For example, some years we are told we can purchase books, articles, and fieldwork equipment using contracts, other years we are told it is prohibited.

In combination, these issues of funding unpredictability made it difficult for us to give clear statements of what we could and could not support when people asked us for research or advisory assistance with their problems. The uncertainty about the federal budget made some contracted researchers uneasy about their job security, fears that we could not, in good faith, waive away, even when we were fairly certain our funding would be safe. Funding concerns also made me cautious when talking with potential new group members, as I could no longer say with any certainty how long we would be able to retain them or even be sure we could support the travel and equipment needed to execute their research.

Yet, in some ways, funding issues of all sorts are predictable parts of the implementation context within a large, federal organization. Several features of TRG's design helped us handle these inevitabilities. We were fortunate that contracted researchers were employed through multiple contracts used to support our host organization. This meant we were never vulnerable to losing the entire team if there was a problem with one contract or if the company holding the contract changed.

Because funding was associated with the capability as a whole, rather than linked to specific projects, we were not constantly having to look for new lines of funding at a time when such lines were being cut or delayed. Also, the group's funding was imbricated with the culture center's budget and capability. So, had somebody targeted us specifically for cuts, it would have been very difficult for them to do so without simultaneously 
harming the culture center, actions that would have been far more visible and harder to justify.

\section{Positioning:}

The positioning of the group within the Marine Corps' culture center made sense as a way to safely launch and protect the initiative in an environment where we had strong institutional support and the advocacy of several influential leaders. Additionally, the culture center's director allowed us to make use of the center's physical and administrative infrastructure. The importance of this last benefit cannot be overstated. Had I been forced to learn about all the byzantine programming, budgetary, contractual, administrative, and legal aspects of running a stand-alone organization within the Marine Corps, the group would never have gotten started.

However, positioning within the culture center also has had a few downsides. Internally, some individuals within the culture center resisted TRG's presence. They did not understand the mission of the research group and resented the presence of researchers who did not seem to contribute much to the training and education missions of the center. During the early years, I spent a great deal of time trying to socialize the purpose of the group and highlight the benefits we brought to the culture center. However, military personnel change every two or three years and some people with more enduring positions were simply determined to misunderstand the roles we played. I gradually realized that I was in a never-ending cycle of advocacy and argument with people who ultimately had no influence over me or TRG's function. Interestingly, once I stopped trying to convince people and simply asserted what we do, many of our internal problems stopped or died down. In retrospect, this outcome should have been predictable based on my understanding of the discursive patterns of the Marine Corps supporting establishment. There are still some internal tensions and they can be frustrating for new researchers, but the strategy of asserting rather than persuading does work. This strategy might have been less successful with less supportive leadership or if I had not learned to be less diplomatic and more forceful in my interactions.

Externally, the position within the culture center sometimes made it difficult for people to understand the broader purpose of the research group. People understandably assumed that we did research only on issues supporting the culture center's mission, studies of "cultures" or terrorism. It was difficult for them to understand why we would be involved in studying Marines and Marine Corps organizations. Consequently, we were not the first organization people thought of when seeking research or advice on these issues. Over time this made it difficult 
to gain access to discussions of problems and decision-makers without an unrealistic level of constant, active support from senior leaders.

One alternative to direct support from senior leaders would have been for me, as the group's director, to engage extensive salesmanship and buzzword chasing to create attention and demand signal for TRG'S work. This is a common strategy in DoD research circles. In addition to my personal disinterest and lack of skill in these activities, I felt they would have led the group down a path that undermined our original intent, especially with regard to critiquing problem framing. Another option would have been to move the group to another organization where its function would be more noticeable and understandable to outside stakeholders. However, during the time period in which such a move could have been made, we judged the internal command climates of all potential receiving organizations would have made it difficult to continue with our original intent. The risk of being turned into an office of deskbound policy analysts was too high. We have overcome this positional weakness to some degree through the good work done by the researchers, but it does make our access to important issues, problems, and decision-makers somewhat personality dependent.

\section{Personnel structure:}

The most intractable implementation challenge for the research capability has been personnel. Our original for the research group involved quickly transitioning our personnel from contractor to government status. This shift was made impossible by an unanticipated hiring freeze, budget sequestration, and other organizational changes. This set of circumstances has left us with a structure where I, as the group's director, am the only government employee. All the research personnel, as well as the group's deputy and our research assistant, are contractors. The problems associated with recruiting specific types of scientific personnel through different types of contracts are very complex. However, to give one example, the culture center uses a type of contract in which the government must describe only the capability to be delivered and cannot specify the way a company provides it or the qualifications of the personnel they hire to do the work. In effect, this means I cannot even tell a company what disciplinary backgrounds or degree level I need, let alone participate in the recruiting, selection, and interviewing of candidates. There is a short window in which the government client can reject an individual the company has hired, but the process is neither swift nor easy.

To further complicate matters, contracting company human resource departments often have little experience with how to assess the quality of a scientific resume. They may not even be able to make to make 
distinctions among disciplines, such as knowing that a political scientist and a sociologist are not the same, or subfields, such as understanding that biological and cultural anthropologists have very different capabilities. So, we are left with a situation where it is quite possible to need a PhD level cultural geographer, but have the company hire somebody with an MA in theology. While we did manage to assemble a good initial group of research personnel and to bring on new researchers as needed, it has been in spite of, rather than because of, normal contracting processes.

The use of contracts to provide the bulk of research group personnel created a number of other problems, as well. One of the most obvious was that, as the only government official within the group, much of my time was consumed by "government only" administrative responsibilities. This severely impaired my ability to maintain my own scholarship and reduced my credibility as a scientific leader inside and outside the group. A less obvious consequence involved our intersection with the large presence of other contractors across nearly all DoD activities. When the group's researchers conducted critical assessments of policy development or training, they inevitably were critiquing the work of other contracting companies, something that is frowned upon, when not prohibited outright. This negatively affected the level of detail provided in some reports and had a chilling effect on my willingness to consider supporting some lines of research where I knew we would be looking at the performance of other contractors. Lack of government status also inhibited researcher participation in implementation. Contracted researchers can and do advise on implementing scientific findings. What they cannot do is represent government positions or make decisions that entail government resources. Several of the group's researchers have become adept at advising, but are still limited in the roles they can play during implementation.

However, the most damaging effect of our personnel situation was that it limited researcher participation in the trust networks civilian and military leaders use to inform their decision-making. As I have described elsewhere (Fosher 2015), leaders in military organizations rely heavily on trust relationships with scientists or intermediaries to help them:

- assess researcher qualifications,

- determine what research to support,

- identify which claims to accept, and

- decide how to integrate results.

Although many of the group's researchers are trusted by decisionmakers, their contractor status always inserts some distance and caution into the relationship. Regardless of how pure your intentions, it is difficult to position yourself as an honest broker when the person you are advising 
knows your company is dependent on future contracts.

\section{Successes, challenges, and lessons learned}

Successes:

Despite the implementation challenges described above, the group has had a surprising number of successes. It is not as easy as one might think to explain the group's successes to an external audience, even one familiar with anthropology outside the academy. Implementation in military organizations sometimes can take years and may be partial or results may be adopted in unexpected, yet positive ways. Our most wellknown project in the early years can illustrate various points on the spectrum of success. In late 2010, one of our researchers, Frank Tortorello, became interested in the way the Marine Corps was framing issues of stress and resilience. Concerned with the trend toward biological reductionism he was seeing, he began to look a critical analysis of discourse and practice surrounding the concept of resilience. The work soon caught the attention of a couple of senior leaders in the service and we were able to expand both the researcher's participation in problem framing and policy development and the research project itself (Marcellino and Tortorello 2015; Tortorello 2014; Tortorello and Marcellino 2013). Over the years, responsibility for developing programs and guidance on resilience has shifted many times. With each shift, the shape of the implementation opportunities changed. One organization was focused on creating top-level guidance for implementation by other organizations. Another organization was focused on developing resilience training. Still another was interested in screening individuals for likely resilience levels at some point during recruiting. This made for a shifting, complex, and often frustrating implementation landscape.

The lead researcher's participation in meetings and working groups did influence the way the service approached the issues, although never as fully or quickly as he would have preferred. In particular, it was an important part of keeping open a line of discussion about the potential influence of education and training on Marines' ability to conceptualize and respond to stress. This line of discourse was and is essential to making it possible for the Marine Corps to consider programs and actions that are not exclusively focused on biological aspects of stress. Likewise, the results of the research were not adopted as fully as he had hoped. Some concepts made their way into guiding documents. Some applied products got used by one command or another. His insights were never fully integrated across the spectrum of Marine Corps efforts. However, although the research ended several years ago and he has since moved on to another job, we are still seeing the effects of his work. In the month that I am writing this, we got a request for advice and products to help shape 
the approach to building resilience in a Marine Corps organization, a request that was based on somebody seeing one small product that he had developed.

Other projects have followed similar trajectories. Implementation irarely happens at a wholesale scale. There seem to be two main patterns that characterize efforts that are successful over time. The first is the continuing presence of the researcher over long implementation timelines to help organizations figure out how to adopt ideas within their particular constraints. This pattern was anticipated in the design of the research group. The other pattern was not something I had thought of in the group's design. Projects that are successful are those where the lead researcher or his/her team are willing to develop a very broad range of project outcomes. In the case of the resilience project, the researchers developed scholarly publications, applied white papers, briefs, classes, curriculum support materials, advisory memos, what must have felt like an endless stream of one page project overviews targeted to different audiences, annotated bibliographies, and a collection of releasable interview transcripts. These products served two purposes. The first was symbolic. It was useful to be able to point to all the outcomes of the project when the use of resources or time was questioned. The second purpose was more substantive. Practitioners with little time were much more likely to engage with us and the broader project if they first encountered it through a product that was framed in ways that spoke to their own concerns. So, somebody charged with weaving resilience into a training schedule might not read an advisory memo or applied report, but might pick up an example of a training scenario and contact us as a result.

\section{Challenges and lessons learned:}

It is always tempting to focus on individual successes in projects or overcoming obstacles. Yet, our primary goal had not been individual successes, but rather progress in improving the ability of the Marine Corps to make effective and appropriate use of social and behavioral scientists and science. I tried to keep an eye on that larger goal when talking to leaders about the group and its long-term viability. In 2012, when it became apparent that we would not be able to structure or staff the group as intended, I recommended that we begin dismantling the group. Interestingly, despite my perceptions of lack of success in developing the capability, we were asked to keep the group running and see what might happen over the next several months or years. I have revisited this question with leaders a few times since and each time we have been asked to keep things going.

In my experience within DoD organizations and with military and former military leaders, this type of long-term vision and institutional 
patience is characteristic of "old hands" within the supporting establishment. They know that sometimes it is necessary to keep a pilot light level of capability viable and wait for the time to be right to make a decision about fully institutionalizing it or shutting it down. While the continued interest is heartening, this has, of course, created a situation with its own set of challenges, including:

- expectation of the originally intended performance despite structural impediments

- staff concerns about job security

- difficulties in managing long research horizons

- continuing administrative demands that decrease my ability to maintain credibility as a researcher

- the need to balance the original research mission with increased support to the day-to-day functions of our host organization.

As of this writing, the final status of the research group remains unclear. Yet, we continue to have good demand signal from a wide range of Marine Corps and DoD organizations. Researchers still tell me that they feel the chance of having an effect on the organization and the lives of Marines outweighs the frustrations and impediments they encounter. So, as Marines say, we endeavor to persevere. ${ }^{9}$

In hindsight, while there are some aspects of the implementation challenges that would have been difficult to change, such as the timing of federal budget sequestration or my own personality limitations as a leader, there are some lessons learned that are transferable, three of which merit attention here. First, I could have conducted more detailed interviewing about institutionalization processes before taking the job, when senior leader investment was at its height. This would have helped me anticipate and perhaps more effectively mitigate problems when stated intentions about the group fell through. At the time I was asked to set up the group, I was still learning about a common DoD cultural pattern related to the gap between senior leader intention and their ability to execute. I believe leaders sincerely intended to follow through on their intentions with regard to things like moving the research personnel structure from contract to government. When they were unable to do so, it seemed like a major issue to me, but as "old hands" they saw it as a normal hiccough in trying to get things done in a large bureaucracy. They expected that I would understand and adapt the capability to the new reality. I have been able to adapt it to some extent, but not to the point

\footnotetext{
${ }^{9}$ The phrase "endeavor to persevere" was taken from a scene in the 1976 western, The Outlaw Josey Wales in which a Native American is describing mistreatment by and eventual war against the Union. In my experience, in the supporting establishment, the phrase is most commonly used when what one is persevering against is bureaucratic drag.
} 
where it is fully meeting the original intent.

Second, I could have established a more rigorous pattern of reporting the implications of implementation problems to the organization's leaders. From time to time, I would meet with them and connect the dots between an implementation obstacle and our inability to conduct a particular project. However, I tended to focus on finding solutions rather than reporting problems. The Marine Corps has a strong institutional orientation toward finding ways to get the job done in spite of obstacles. It is rare to go a day without hearing sayings like "adapt and overcome" or "semper gumby." I have worked hard to maintain awareness of how I am influenced by the discourses and cultural patterns within military organizations, as I recognize the inherent dangers they can present to an anthropologist. However, in this case, I didn't recognize the effect my choice to focus on adapting would have on the group. Had I more routinely and forcefully reminded organizational leaders of the problems we faced and the implications for our work, we might have been able to mitigate or overcome more of the obstacles. Of course, it is also possible that they would have chosen to shut the group down.

These two lessons learned imply a third, the way "normal" tends to shift as you make one small adjustment after another. In the case of the adaptations made for and by the research group, I do not perceive this to have been a major problem. In a group of social scientists accustomed to critically analyzing actions and context, we tend to notice shifts in what counts as business as usual. Also, I maintain a professional network of individuals with varying opinions about my work with the military and encourage my researchers to do the same. Conversations along these networks keep me wary of slippery slopes (Fosher 2010).

\section{Conclusion: next steps for the literature of practice and for TRG}

Although it is beyond the scope of this report to delve into it, the issues outlined above are clearly not limited to military organizations and they suggest some things about where we might work on the literature of practice. Anthropology has a long history with studying implementation in government programs and is no stranger to the study of bureaucracy (Hoag 2011; Hull 2012; Pressman and Wildavsky 1984; Zabusky 1995). There also are plenty of accounts of similar problems and efforts to solve them in other sectors in which practicing or applied anthropologists work in conjunction with large institutions and bureaucracy, such as medical anthropology, international health, and development (Inhorn and Wentzell 2012; Nolan 2002). Although I am less familiar with anthropology in business, I would imagine these types of challenges play out in large organizations the private sector as well. Likewise, we have substantial literatures, such as those mentioned in the overview section 
above, providing critical perspectives on anthropological engagement in military organizations that have corollaries in other sectors. We also have a small, but growing literature of practice that describes what it is like to work within these sectors (Nolan 2013).

There are two areas in the literature I would prioritize for additional work. The first is in comparing anthropological practice in large institutions or bureaucracies across sectors. The gap I perceive is less about producing an edited volume of studies of or research done for such organizations. Rather, I think what would help move us forward is a comparison of the full range of anthropological practice, including, but not limited to research, within such organizations and the challenges and solutions we find for getting anthropological perspectives used. The second area where I believe we have some work to do might best be characterized as methods of practice. Traditional and even applied methods classes in anthropology tend to focus on research methods. Yet research is only one part of what practicing and applied anthropologists do. We advise, craft policies and procedures, help frame problems, build working relationships, and many other types of work. Although some standard reference materials have started to address implementation and policy engagement, there is more to do (Schensul 1999). There are relatively few resources for students or professionals looking for insights that will help them get results implemented or get things done by means other than research.

I'll conclude with a final note on implementing the research group within the Marine Corps context. It is unclear what the long-term trajectory and impact of TRG will be. If the overall goal has been to get some fieldwork-based social science research and advice into discussions where it has traditionally been absent, then we have succeeded. If the goal is to ensure this kind of research and advising continues to happen in ways that are not dependent on the personality and motivations of those of us who started the group, then we aren't yet done. The capability is not sufficiently institutionalized to stand without external support. Yet a Marine colleague recently reminded me of the secondary impacts of a capability like ours, even if it does not survive in the end. He pointed out that we have spent more than half a decade influencing the thinking of Marines who will take that thinking into positions of greater responsibility and, eventually, into their post-Marine Corps civilian lives. He also remarked that we will have added to the pool of researchers in our disciplines who understand the complexity of the military as a social institution and, perhaps more importantly, understand what it takes to go from idea to implementation in a large bureaucracy. 


\section{References}

Albro, Robert, et al. 2012 Anthropologists in the securityscape : ethics, practice, and professional identity. Walnut Creek, CA: Left Coast Press, Inc.

Albro, Robert, et al. 2009 AAA Commission on the Engagement of Anthropology with the US Security and Intelligence Communities (CEAUSSIC) Final Report on The Army's Human Terrain System Proof of Concept Program. American Anthropological Association.

Deitchman, Seymour J. 2014 [1976] The Best-Laid Schemes : A Tale of Social Research and Bureaucracy. (2nd Edition). Quantico, VA: Marine Corps University Press.

Dilulio, John J. 2014 Bring back the bureaucrats : why more federal workers will lead to better (and smaller!) government. West Conshohocken, PA: Templeton Press.

Elmendorf, Douglas W. 2015 Federal Contracts and the Contracted Workforce: Response to Inqury from Congressional Representative Chris Van Hollen. Congressional Budget Office, U.S. Congress.

Fosher, Kerry 2010 Yes, Both, Absolutely: A Personal and Professional Commentary on Anthropological Engagement with Military and Intelligence Organizations. In Anthropology and global counterinsurgency. J.D. Kelly, B. Jauregui, S.T. Mitchell, and J. Walton, eds. Pp. 261-271. Chicago: The University of Chicago Press.

Fosher, Kerry 2015 Reflections on Current Research: Science and Scientists in Military Organizations. Journal of Culture, Language, and International Security 1(2):47-58.

Hoag, Colin 2011 Assembling Partial Perspectives: Thoughts on the Anthropology of Bureaucracy. PoLAR: Political and Legal Anthropology Review 34(1):81-94. https://doi.org/10.1111/j.1555-2934.2011.01140.x

Hull, Matthew S. 2012 Government of paper : the materiality of bureaucracy in urban Pakistan. Berkeley: University of California Press. https://doi.org/10.1525/california/9780520272149.001.0001

Inhorn, Marcia Claire, and Emily A. Wentzell 2012 Medical anthropology at the intersections : histories, activisms, and futures. Durham: Duke University Press. https://doi.org/10.1215/9780822395478

Jogalekar, Ashutosh 2012 The perils of translational research. In Scientific American (The Curious Wavefunction), Vol. 2017: Scientific American.

Marcellino, William M., and Frank Jr. Tortorello 2015 'I Don't Think I Would Have Recovered': A Personal and Sociocultural Study of Resilience among US Marines. Armed Forces \& Society 41(3).

Nolan, Riall W. 2002 Development anthropology : encounters in the real 
world. Boulder, Colo.: Westview Press.

Nolan, Riall W. 2013 The handbook of practicing anthropology.

Chichester, West Sussex; Malden, MA: Wiley-Blackwell.

https://doi.org/10.1002/9781118486597

Peacock, James, et al. 2007 AAA Commission on the Engagement of Anthropology with the US Security and Intelligence Communities Final Report. American Anthropological Association.

Pressman, Jeffrey L., and Aaron B. Wildavsky 1984 Implementation : how great expectations in Washington are dashed in Oakland : or, why it's amazing that federal programs work at all, this being a saga of the Economic Development Administration as told by two sympathetic observers who seek to build morals on a foundation of ruined hopes. Berkeley: University of California Press.

Price, David H. 2011 Weaponizing anthropology : social science in the service of the militarized state. Oakland, CA: AK Press.

Rubinstein, Robert A. 1986 Reflections on Action Anthropology: Some Developmental Dynamics of an Anthropological Tradition. Human Organization 45(3):270-279. https://doi.org/10.17730/humo.45.3.j0r1w186w2162140

Rubinstein, Robert A., Kerry B. Fosher, and Clementine K. Fujimura 2012 Practicing military anthropology : beyond expectations and traditional boundaries. Sterling, Va.: Kumarian Press.

Schensul, Jean J. 1999 Using ethnographic data interventions, public programming and public policy. Walnut Creek, Calif.: Altamira Press.

Tortorello, Frank Jr. 2014 Stress and Resilience in the U.S. Marine Corps. Marine Corps Gazette 98(6):30-33.

Tortorello, Frank Jr., and William M. Marcellino 2013 Military Resilience, Suicide, and Post-Traumatic Stress: What's Behind it All? In Foreign Policy: Best Defense. T. Ricks, ed, Vol. 2017.

United States Department of Defense 2017 About the Department of Defense (DOD), Vol. 2017.

Woolf, S. H. 2008 The meaning of translational research and why it matters. JAMA 299(2):211-213. https://doi.org/10.1001/jama.2007.26

Zabusky, Stacia E. 1995 Launching Europe: An Ethnography of European Cooperation in Space Science. Princeton: Princeton University Press. 
Kerry Fosher is a practicing cultural anthropologist who focuses on the integration of social science into education, policy, and decisionmaking in military organizations. In her current role, as Director of the Translational Research Group at Marine Corps University she directs the research projects of an interdisciplinary staff of social scientists who conduct field research on a broad range of topics of interest to the Marine Corps and provide social science advice to military and senior civilian leaders. She speaks regularly on ethics, security anthropology, and crafting approaches to culture in military organizations. Her current work focuses on how military organizations perceive and consume science, theoretical maturation of the domain of practicing anthropology, and broader issues of sustainably integrating social science and social scientists in government organizations. She earned her PhD in cultural anthropology from the Maxwell School at Syracuse University. 